\title{
IDEOLOGIAS GEOGRÁFICAS E INDÚSTRIA CULTURAL
}

IDEOLOGÍAS GEOGRÁFICAS Y INDUSTRIA CULTURAL

Donique Fernanda $\operatorname{Setin}^{\mathrm{A}}$

\footnotetext{
${ }^{\text {A }}$ Universidade Estadual Paulista (UNESP), São Paulo, SP, Brasil
}

Recebido em: 20/07/2021 | 28/07/2021 DOI: $10.12957 /$ tamoios.2021.60783

Correspondência para: Monique Fernanda Setin (monique_setin@yahoo.com.br)

\section{Resumo}

Este artigo procura contribuir com o estudo proposto por Moraes (1988) sobre ideologias geográficas. O objetivo é pensar o tema da cultura, dos meios de comunicação e da indústria cultural. A valorização subjetiva do espaço se constrói e se dissemina por meio da cultura e é fundamental compreendê-la para entender a valorização objetiva do espaço. A metodologia utilizada para a realização deste artigo é a pesquisa bibliográfica, leitura e interpretação de texto. Defendemos a importância dos autores da Teoria Crítica a fim de contribuir com o aprimoramento do pensamento geográfico.

Palavras-chave: Ideologias Geográficas; Cultura; Indústria Cultural.

\section{Resumen}

Este artículo busca contribuir al estudio propuesto por Moraes (1988) sobre las ideologías geográficas. El objetivo es pensar en el tema de la cultura, los medios de comunicación y la industria cultural. La valoración subjetiva del espacio se construye y difunde a través de la cultura y es fundamental comprenderla para comprender la valoración objetiva del espacio. La metodología utilizada para la realización de este artículo es la investigación bibliográfica, la lectura y la interpretación de textos. Defendemos la importancia de los autores de la Teoría Crítica para contribuir a la mejora del pensamiento geográfico.

Palabras clave: Ideologías geográficas; cultura; industria cultural 


\section{INTRODUÇÃO}

Este artigo procura participar da discussão sobre a temática acerca das ideologias geográficas proposta pelo geógrafo Antônio Carlos Robert de Moraes em seu livro chamado de IDEOLOGIAS GEOGRÁFICAS: Espaço, Cultura e Política no Brasil (1988). Precisamente, o foco deste artigo será dado a relação entre ideologias geográficas e ao estudo da indústria cultural e cultura de massas.

O ponto de partida para compreender tal temática é o espaço geográfico, uma vez que o espaço é a categoria de estudo da Geografia. O processo de valorização objetiva do espaço é condicionado pelas consciências individuais, pelas ideologias, pelas culturas, ou seja, para que ocorra a valorização objetiva do espaço é necessário a valorização subjetiva do mesmo.

A valorização subjetiva do espaço são ideias, valores, concepções, visões de mundo sobre o espaço, que se materializam nas nossas práticas cotidianas e que impulsionam a valorização objetiva do espaço. As concepções acerca do espaço são disseminadas através das relações sociais, dos documentos vinculados ao Estado, por meio da cultura e dos meios de comunicação. Desta forma, é fundamental compreender as produções culturais e seus conteúdos a fim de extrair delas as ideologias geográficas, para assim, entender a valorização objetiva do espaço. Sabe-se que há uma relação entre cultura e meios de comunicação. Além desses meios veicularem concepções sobre o espaço, também foram criados com o intuito de integrar o território brasileiro no que tange ao imaginário social e propagar ideias ligadas ao governo durante o século $\mathrm{XX}$. $\mathrm{O}$ objetivo desse artigo é responder as seguintes questões: $\mathrm{O}$ que é Cultura? O que é Cultura de Massas e o que é Indústria Cultural? A metodologia utilizada para responder essas questões foi a pesquisa bibliográfica, leitura e interpretação de texto. Os principais autores estudados são: Said (2011), Coelho (1986), Adorno e Horkheimer (1985), Benjamin (1994), Mcluhan (1964) e Moraes (1988).

\section{Cultura, meios de comunicação e indústria cultural.}

Neste artigo procuramos relacionar ideologias geográficas, cultura, meios de comunicação e indústria cultural. Vimos que, para que ocorra a valorização objetiva do espaço, é necessária a valorização subjetiva dele. A valorização subjetiva envolve ideias, valores, concepções e visões de mundo sobre o espaço que se materializam nas nossas práticas cotidianas e que impulsionam a valorização objetiva do espaço. As concepções acerca do espaço são disseminadas através das relações sociais e dos documentos vinculados ao Estado por meio da cultura e dos meios de comunicação. Dessa forma, é fundamental compreender as produções culturais e seus conteúdos a fim de extrair delas as ideologias geográficas, para assim entender a valorização objetiva do espaço.

Sabe-se que há uma relação entre cultura e meios de comunicação. Além desses meios veicularem concepções sobre o espaço, eles também foram criados com o intuito de integrar o 
território brasileiro no que tange ao imaginário social e propagar ideias ligadas ao governo durante o século XX. O objetivo deste tópico é responder às seguintes questões: o que é cultura? O que é indústria cultural? Qual a diferença entre cultura de massas e cultura industrial? O que é e qual o papel dos meios de comunicação? Os principais autores estudados são Coelho (1986), McLuhan (1964), Adorno e Horkheimer (1985), Benjamin (1994) e Said (2011).

Antes de tudo, é importante conceituar cultura, para depois adentrarmos os estudos sobre cultura de massas, indústria cultural e meios de comunicação. Este artigo se inspira no conceito de cultura defendido por Said (2011, p. 4), que em primeiro lugar significa:

Quando emprego o termo, ele significa duas coisas em particular. Primeiro, "cultura" designa todas aquelas práticas, como as artes de descrição, comunicação e representação, que têm relativa autonomia perante os campos econômico, social e político, e que amiúde existem sob formas estéticas, sendo o prazer um de seus principais objetivos. Incluem-se aí, naturalmente, tanto o saber popular sobre partes distantes do mundo quanto o conhecimento especializado de disciplinas como a etnografia, a historiografia, a filologia, a sociologia e a história literária.

Em segundo lugar:

Com o tempo, a cultura vem a ser associada, muitas vezes de forma agressiva, à nação ou ao Estado; isso "nos" diferencia "deles", quase sempre com algum grau de xenofobia. A cultura, neste sentido, é uma fonte de identidade, e aliás bastante combativa, como vemos em recentes "retornos" à cultura e à tradição. (SAID, 2011, p. 5)

Para Said (2011), por um lado, a cultura possui um significado positivo quando relacionado ao conhecimento, no entanto, por outro, ela possui um significado negativo quando associada ao Estado. $\mathrm{O}$ autor, em sua obra, faz uma relação entre Imperialismo e cultura. Ao longo da história, os grandes impérios, além de dominar a economia e a política de povos e territórios distantes, dominavam também suas culturas. Esses impérios elaboravam discursos sobre os povos latinos, africanos e asiáticos que os colocavam como subalternos, submissos e inferiores. É importante perceber quem possui o poder de contar uma história e quem não tem o mesmo poder, uma vez que isso define qual versão da história será contada, e é aqui que a relação entre cultura e Imperialismo se encontra.

Sabe-se que é o Estado-Nacional quem cria a infraestrutura necessária para a existência dos meios de comunicação, os quais propagam conhecimentos e representações pelo território brasileiro. A cultura disseminada pelos meios de comunicação é chamada de cultura de massas, porém há um debate acerca de cultura de massas e indústria cultural - ou melhor, a indústria cultural divulga uma cultura de massa. Coelho (1986) prefere dizer que a indústria cultural divulga uma cultura industrializada ou uma cultura industrial, uma vez que essa cultura não é produto das massas, mas sim de grandes corporações. É nesse debate que adentramos a seguir. 
Quando surge a cultura de massas ou cultura industrializada? Ela surge na Europa durante a segunda metade do século XIX, a partir da junção de jornais, romance de folhetim, teatro de revista, opereta e cartaz; todos juntos formaram um sistema. A indústria cultural, os meios de comunicação de massa e a cultura de massa nascem em resposta ao processo de industrialização. Sobre a industrialização, Coelho (1986, p. 11) diz:

É esta, através das alterações que produz no modo de produção e na forma do trabalho humano, que determina um tipo particular de indústria (a cultural) e de cultura (a de massa), implantando numa e noutra os mesmos princípios em vigor na produção econômica em geral: o uso crescente da máquina e a submissão do ritmo humano de trabalho ao ritmo da máquina; a exploração do trabalhador; a divisão do trabalho. Estes são alguns dos traços marcantes da sociedade capitalista liberal, onde é nítida a oposição de classes e em cujo interior começa a surgir a cultura de massa. Dois desses traços merecem uma atenção especial: a reificação (ou transformação em coisa: a coisificação) e a alienação. Para essa sociedade, o padrão maior (ou único) de avaliação tende a ser a coisa, o bem, o produto, a propriedade: tudo é julgado como coisa, portanto tudo se transforma em coisa - inclusive o homem. E esse homem reificado só pode ser um homem alienado: alienado de seu trabalho, trocado por um valor em moeda inferior às forças por ele gastas; alienado do produto de seu trabalho, que ele mesmo não pode comprar, pois seu trabalho não é remunerado à altura do produzido; alienado, enfim, em relação a tudo, alienado de seus projetos, da vida do país, de sua própria vida, uma vez que não dispõe de tempo livre, nem de instrumentos teóricos capazes de permitir-lhe a crítica de si mesmo e da sociedade.

A cultura produzida em série a fim de atender um amplo mercado se transforma em mercadoria; enquanto tal, ela deve ser consumida pelo seu comprador/consumidor. Dentro dessas condições, a cultura perde seus elementos de crítica e conhecimento e se transforma em uma mercadoria, produzida por uma indústria que segue um padrão, a fim de satisfazer a necessidade do público, que foi criada por essa mesma indústria - além de o público não ter tempo livre o suficiente para questionar tal indústria, tendo em vista a longa jornada de trabalho enfrentada pelas trabalhadoras e pelos trabalhadores. Dessa forma, os produtos da cultura enquanto objeto de consumo passam a ser descartados e destruídos como qualquer outra mercadoria. Sobre o surgimento da indústria cultural, Coelho (1986, p. 12) diz:

Esse é o quadro caracterizador da indústria cultural: revolução industrial, capitalismo liberal, economia de mercado, sociedade de consumo. É esse o momento histórico do aparecimento de uma cultura de massa - ou, pelo menos, o momento pré-histórico. É que, de um lado, surgem como grandes instantes históricos dessa cultura os períodos marcados pela Era da Eletricidade (fim do século XIX) e pela Era da Eletrônica (a partir da terceira década do século XX) - quando o poder de penetração dos meios de comunicação se torna praticamente irrefreável. E, por outro lado, na medida em que a cultura de massa está ligada ao fenômeno do consumo, o momento de instalação definitiva dessa cultura seria mesmo o século XX, onde o capitalismo não mais dito liberal mas, agora, um capitalismo de organização 
(ou monopolista) criará as condições para uma efetiva sociedade de consumo cimentada, em ampla medida, por veículos como a TV.

A indústria cultural propaga uma cultura que é de massas, projetada através dos meios de comunicação com forte apelo consumista. O autor McLuhan (1964) elabora um importante estudo sobre os meios de comunicação. Ele focaliza nos efeitos que os meios causam nos indivíduos. Sua preocupação não é com o conteúdo que esses meios veiculam, mas com os efeitos gerados pelos próprios meios nos indivíduos; sua famosa frase é "o meio é a mensagem".

McLuhan (1964) divide os meios de comunicação entre quentes e frios. Os meios de comunicação são a palavra falada, escrita e impressa, o número, o dinheiro, o vestuário, a eletricidade, o carro, a fotografia, o cinema e a televisão, entre outros. Os meios de comunicação são extensões do ser humano, eles criam ambientes que afetam o ser humano tais ambientes são processos ativos, não passivos. Os meios de comunicação, metaforicamente, são como prolongamentos do sistema nervoso central. Não importa o conteúdo do meio, uma vez que o meio é a mensagem, "porque é o meio que configura e controla a proporção e a forma das ações e associações humanas" (MCLUHAN, 1964, p. 23). Todo meio é um meio sem mensagem, uma vez que o conteúdo desse meio é outro meio, por exemplo: a escrita é um meio e seu conteúdo é a fala, esse é outro meio. A mensagem de um meio "é a mudança de escala, cadência ou padrão que esse meio ou tecnologia introduziu nas coisas humanas" (MCLUHAN, 1964, p. 22).

Há uma relação entre mecanização e cinema: aquela ocorre por meio da fragmentação de um dado processo, depois disso, esses fragmentos são colocados em série. Não há causalidade em uma sequência de fragmentos, o que há, é mudança. A eletricidade acabou com a sequência entre as coisas e estas tornaram-se simultâneas; dessa forma, com a velocidade instantânea, passamos a questionar a causalidade das coisas. O cinema nos tirou de um mundo de sequências e nos apresentou um mundo de estruturas e configurações. A mensagem do cinema é a "transição da sucessão linear para a configuração" (MCLUHAN, 1964, p. 27).

Os meios são prolongamento de nós e causam guerras internas em nós mesmos. Quando recebemos excesso de informação, sofremos com crises de esgotamento nervoso e mental, assim, os efeitos da tecnologia afetam nossa vida psíquica. $\mathrm{O}$ efeito do meio é intenso, porque seu conteúdo é outro meio. O conteúdo do filme é um romance, seu efeito não está relacionado ao seu conteúdo. Os efeitos do meio afetam os sentidos e percepções da audiência. Os meios são extensões dos nossos sentidos, eles mudam nossos sentidos, prolongam alguns, mas amputam outros. Quando um sentido é estimulado, os outros também são afetados. Dessa forma, os indivíduos tornam-se servos dos meios e passam a idolatrá-los. Nosso sistema nervoso central, a fim de suportar a irritação social, se expande para fora de si através dos meios. Isso mostra que o próprio corpo não consegue mais amenizar e proteger o sistema nervoso central. Ao se prolongar, há uma amputação dos nossos sentidos e nos tornamos servos desse prolongamento ou meio.

$\mathrm{O}$ rádio e o cinema são meios quentes, o telefone e a televisão são meios frios. Os meios quentes e os meios frios causam efeitos diferentes nos indivíduos. O meio quente é sinônimo de alta definição, o meio frio é sinônimo de baixa definição. $O$ meio quente 
prolonga apenas um dos nossos sentidos. Nas palavras do autor: "um meio quente é aquele que prolonga um único de nossos sentidos e em 'alta definição'. Alta definição se refere a um estado de alta saturação de dados" (MCLUHAN, 1964, p. 38). O meio frio ou de baixa definição proporciona pouca informação visual, dessa forma, é necessário que o indivíduo participe e complete a informação recebida. Já os meios quentes fornecem muita informação, por isso os indivíduos pouco participam.

A cultura pode ser quente ou fria. Uma cultura quente é uma cultura letrada, uma cultura fria é uma cultura oral. Ao inserir meios quentes, como o rádio e o cinema, em uma cultura fria, isso provoca um efeito violento nessa cultura e vice-versa. Para o autor, os países subdesenvolvidos, atrasados, são frios; já os países desenvolvidos são quentes. Os indivíduos que vivem nas cidades são quentes, e aqueles que vivem no interior, os rústicos, são frios.

O objetivo do cineasta é transportar o espectador do seu mundo para o mundo do filme. O ser humano letrado aceita essa transposição sem resistência, já o não letrado não aceita essa transposição. Para entender um filme é preciso saber ler e escrever. Uma audiência não letrada não aceita o aparecimento e desaparecimento de repente de objetos na tela, não aceita fixar os olhos na tela em uma visão em perspectiva, não se conforma com a linearidade e a sequência cinematográfica. Contudo, sabemos que atualmente isso acontece de modo diferente. Muitas crianças, antes de saberem ler e escrever, assistem a filmes e conseguem entendê-los. O que acontece, nos dias de hoje, é que somos bombardeados por imagens vindas desses meios de comunicação, estamos inseridos em um processo de aprendizado por imagens.

O cinema possui uma grande capacidade de armazenar e transmitir informações. Um livro necessitaria de páginas para descrever uma cena. Dessa forma, "o cinema levou o escritor à economia verbal e ao simbolismo em profundidade, onde o filme não pode fazer-lhe concorrência" (MCLUNHAN, 1964, p. 324). O cinema surge a partir do romance moderno. O filme é resultado de movimentos rápidos; além de produzir sonhos na audiência, ele se aproxima da vida real e a supera por meio da ilusão. O cinema e a publicidade oferecem como produto o sonho. Ambos vendem sonhos, por isso, o filme distribui, aos pobres, o papel de riqueza. $\mathrm{O}$ cinema faz parte de uma sociedade do consumo: além de estimulá-lo, ele oferece ao espectador um mundo de solidão, fantasia e sonho. No entanto, para produzir um filme, é necessária a junção de vários trabalhadores individuais.

Os autores da Escola de Frankfurt, principalmente Adorno e Horkheimer na obra $A$ dialética do esclarecimento (1985), também fazem uma relação entre cultura, consumo e publicidade. Ou melhor, a indústria cultural, através dos meios, cria necessidades nos indivíduos durante seu tempo livre. Ninguém consegue escapar da indústria da diversão. Ela dissemina concepções de mundo e os indivíduos se apropriam dessas ideias e, de acordo com ela, agem. A seguir, adentramos na referida obra dos autores da Teoria Crítica.

Para Adorno e Horkheimer (1985, p. 99), "a cultura contemporânea confere a tudo um ar de semelhança. O cinema, o rádio e as revistas constituem um sistema. Cada setor é coerente em si mesmo e todos o são em conjunto". O modelo da cultura é "a falsa identidade do universal e do particular" (ADORNO; HORKHEIMER, 1985, p. 100). Toda cultura destinada às massas é igual, uma vez que está subordinada ao poder do monopólio. 
$\mathrm{O}$ cinema e o rádio são negócios que se definem como indústria. O rádio e o cinema utilizam a arte como ideologia a fim de justificar os bens culturais produzidos. A indústria cultural produz bens culturais em larga escala e os disseminam pelo globo terrestre. Os bens culturais produzidos são padronizados e o objetivo é satisfazer as necessidades criadas pela própria indústria cultural, que manipula as consciências individuais criando necessidades. Através da técnica, a indústria cultural domina a racionalidade individual e os economicamente mais fortes dominam tal indústria. O desejo dos espectadores é produzido e a reação da audiência é controlada pela indústria, o público transforma-se em consumidor. Os especialistas planejam e colocam os bens culturais enquanto estatísticas. Dessa forma, constatamos que há uma relação entre cultura e economia, uma vez que o monopólio cinematográfico é dependente do monopólio bancário.

Os indivíduos recorrem às mercadorias produzidas pela indústria cultural durante seu tempo livre, que é dominado por tal indústria. Os produtos vendidos pela indústria cultural são fundamentados na mesmice, na repetição, na imitação, na cópia, ou seja, a diferença é ilusão. Em outras palavras, os bens culturais surgem ciclicamente, eles são a reprodução do mesmo, os consumidores devem se contentar com os produtos ofertados e ninguém consegue escapar da indústria cultural. A fórmula da indústria cultural é fazer filmes de modo mais fiel possível e de acordo com a realidade. O objetivo disso é criar uma ilusão de prolongamento entre filme e realidade. $O$ filme não permite a fantasia e o pensamento espontâneo, $o$ pensamento do espectador é controlado e administrado pelos especialistas e o resultado disso é a "atrofia da imaginação e da espontaneidade" (ADORNO; HORKHEIMER, 1985, p. 104).

A indústria cultural, com sua produção em larga escala, acaba criando estereótipos e discursos sociais e espaciais que são apropriados na nossa prática social. Os trabalhadores recorrem aos produtos durante seu tempo livre a fim de se afastarem do trabalho mecanizado, contudo, até seu tempo livre é mecanizado. A arte é reduzida em consumo, entretenimento, diversão, e os trabalhadores se apropriam da ideologia da classe dominante. A ideologia dessa indústria é o negócio, o lucro. Seu poder é procurar satisfazer necessidades criadas por ela mesma - ou seja, a indústria cultural foi quem criou a necessidade de diversão. Para ter prazer é preciso não pensar; diante disso, o pensamento do consumidor é reprimido, destruído, limitado, e somos desacostumados à subjetividade.

O espectador acredita na possibilidade de estar na tela, mas há uma distância entre ele e a tela. A respeito do processo de identificação entre o espectador e a tela, os autores dizem: "A industrial cultural realizou maldosamente o homem como ser genérico" (ADORNO; HORKHEIMER, 1985, p. 120). Isso significa que todos os indivíduos são substituíveis, são mercadorias que podem ser trocadas por outras. A sociedade é reduzida em clientes e empregados, ou seja, objetos. Por conta da padronização, tanto no trabalho como no tempo livre, o indivíduo possui uma falsa identidade, ou seja, a individuação nunca aconteceu, o que há é o ser humano enquanto ser genérico. A arte enquanto mercadoria possui valor de uso, valor de troca e fetiche. Nas palavras dos autores:

O que se poderia chamar de valor de uso na recepção dos bens culturais é substituído pelo valor de troca; ao invés do prazer, o que se busca é assistir e estar informado, o que se quer é conquistar prestígio e não se tornar um conhecedor. O consumidor torna-se a ideologia da indústria da diversão, de 
cujas instituições não consegue escapar. É preciso ver Mrs. Miniver, do mesmo modo que é preciso assinar as revistas Life e Time. Tudo é percebido do ponto de vista da possibilidade de servir para outra coisa, por mais vaga que seja a percepção dessa coisa. Tudo só tem valor na medida em que se pode trocá-lo, não na medida em que é algo em si mesmo. O valor de uso da arte, seu ser, é considerado como um fetiche, e o fetiche, a avaliação social que é erroneamente entendida como hierarquia das obras de arte - torna-se seu único valor de uso, a única qualidade que elas desfrutam. É assim que o caráter mercantil da arte se desfaz ao se realizar completamente. Ela é um gênero de mercadorias, preparadas, computadas, assimiladas à produção industrial, compráveis e fungíveis, mas a arte como um gênero de mercadorias, que vivia de ser vendida e, no entanto, de ser invendível, torna-se algo hipocritamente invendível, tão logo o negócio deixa de ser meramente sua intenção e passa a ser seu único princípio. O concerto de Toscanini transmitido pelo rádio é, de certa maneira, invendível. É de graça que o escutamos, e cada nota da sinfonia é como que acompanhada de um sublime comercial anunciando que a sinfonia não é interrompida por comerciais - "this concert is brought to you as public service". A ilusão realiza-se indiretamente através do lucro de todos os fabricantes de automóveis e sabão reunidos, que financiam as estações, e naturalmente através do aumento de vendas da indústria elétrica que produz os aparelhos de recepção. O rádio, esse retardatário progressista da cultura de massas, tira todas as consequências que o pseudomercado do cinema por enquanto recusa a este. A estrutura técnica do sistema radiofônico comercial torna-o imune a desvios liberais como aqueles que os industriais do cinema ainda podem se permitir em seu próprio setor. Ele é um empreendimento privado que já representa o todo soberano, no que se encontra um passo à frente das outras corporações. Chesterfield é apenas o cigarro da nação, mas o rádio é o porta-voz dela. Ao integrar todos os produtos culturais na esfera das mercadorias, o rádio renuncia totalmente a vender como mercadorias seus próprios produtos culturais. (ADORNO; HORKHEIMER, 1985, p. 131)

O rádio tornou-se a voz do autoritarismo e da publicidade, que comanda o indivíduo. O locutor anuncia as mercadorias sempre iguais, as propagandas dão a falsa impressão de liberdade de escolha; ele ordena o holocausto, assim como a compra de mercadorias. A entonação do locutor tem que ser a mesma do público. A reação do público é imposta pela indústria cultural, está reificada para ele próprio. A vida psíquica do indivíduo é organizada segundo o modelo da indústria cultural. A cultura é uma mercadoria, mas é uma mercadoria paradoxal, uma vez que a cultura não se troca, tampouco se usa.

A cultura é uma mercadoria paradoxal. Ela está tão completamente submetida à lei da troca que não é mais trocada. Ela se confunde tão cegamente com o uso que não se pode mais usá-la. É por isso que ela se funde com a publicidade. (ADORNO; HORKHEIMER, 1985, p. 134)

No capitalismo monopolista, a cultura se funde com a publicidade. O sistema obrigou todo produto ao uso da publicidade, dessa forma, a publicidade "invadiu o idioma, o 'estilo', da indústria cultural” (ADORNO; HORKHEIMER, 1985, p. 134). A publicidade está 
presente tanto nos prédios novos quanto nos antigos, e um filme se monta de acordo com a publicidade.

Sabe-se que há um intenso diálogo entre Adorno, Horkheimer e Benjamin a respeito da cultura. Para Adorno e Horkheimer (1985), o cinema é um negócio que visa ao lucro, isto é, o cinema não é visto enquanto arte. Para Benjamin (1994), a fotografia e o cinema mudaram a natureza da arte, além disso, a arte do cinema se encontra na montagem. Nesse momento, procuramos conhecer de modo introdutório o pensamento de Walter Benjamin (1994), já que esse autor é fundamental para os estudos sobre as transformações artísticas na era da reprodutibilidade técnica, ou seja, durante a modernidade.

Benjamin (1994) explica que a obra de arte sempre foi reprodutível, todavia, esse processo se modifica com a reprodução técnica da obra de arte, principalmente por meio da fotografia e do cinema. O cinema nasce da fotografia. A reprodução técnica da obra de arte permite colocar no mercado, a reprodução em série do original com um toque de novidade. A partir da fotografia, o olho ganhou destaque em relação à mão, isso resultou em um aceleramento no processo de reprodução da imagem. Com a reprodução técnica do som, ela se apropriou das obras de artes tradicionais e as transformou, além de tornar-se uma arte específica. A partir da reprodução técnica do original, ocorre a perda da autenticidade, ou seja, perde-se seu aqui e agora. A reprodução se separa da sociedade e da tradição que a criou, resultando na perda da história e do testemunho do original; para reconstitui-la, é preciso retornar ao lugar em que o original se formou.

A reprodução técnica tem mais autonomia do que a reprodução manual devido a dois fatores: a reprodução técnica (por exemplo, a fotografia) acentua aspectos do original que foge ao olhar natural do indivíduo, além de aproximar o indivíduo da obra de arte. Por um lado, a reprodução técnica desvaloriza a autenticidade e a aura do original. Por outro, a reprodução do original e sua disseminação aproximam o público da arte e tal aproximação produz a renovação da humanidade. Na citação apresentada a seguir, o autor traz o conceito de aura, que permite um resumo do conceito de autenticidade. Nas palavras do autor:

O conceito de aura permite resumir essas características: o que se atrofia na era da reprodutibilidade técnica da obra de arte é sua aura. Esse processo é sintomático, e sua significação vai muito além da esfera da arte. Generalizando, podemos dizer que a técnica da reprodução destaca do domínio da tradição o objeto reproduzido. Na medida em que ela multiplica a reprodução, substitui a existência única da obra por uma existência serial. $\mathrm{E}$, na medida em que essa técnica permite à reprodução vir ao encontro do espectador, em todas as situações, ela atualiza o objeto reproduzido. Esses dois processos resultam num violento abalo da tradição, que constitui o reverso da crise atual e a renovação da humanidade. Eles se relacionam intimamente com os movimentos de massa, em nossos dias. Seu agente mais poderoso é o cinema. Sua função social não é concebível, mesmo em seus traços mais positivos, e precisamente neles, sem seu lado destrutivo e catártico: a liquidação do valor tradicional do patrimônio da cultura. (BENJAMIN, 1994, p. 169) 
Nossa percepção é condicionada natural e historicamente, alterando-se por conta da destruição da aura. A citação a seguir traz a definição de aura:

Em suma, o que é a aura? É uma figura singular, composta de elementos espaciais e temporais: a aparição única de uma coisa distante, por mais perto que ela esteja. Observar, em repouso, numa tarde de verão, uma cadeia de montanhas no horizonte, ou um galho, que projeta sua sombra sobre nós, significa respirar a aura dessas montanhas, desse galho. (BENJAMIN, 1994, p. 170)

O declínio da aura é resultado de dois motivos, que são ligados ao movimento de massas, ou seja, as massas querem que as coisas fiquem mais próximas delas e querem também que as coisas únicas se multipliquem por meio da reprodução técnica. O resultado da reprodutibilidade é que a obra de arte se separa do ritual. Diante de tal separação, a obra de arte ganha uma nova função, que é a política.

No início da criação artística, a obra de arte possuía um valor de culto: ela servia, primeiramente, à magia e, depois, à religião. Dessa forma, as obras de arte não eram criadas para serem vistas, elas ficavam em lugares secretos e sagrados. Isso se modifica na medida em que a obra de arte se destaca do ritual. Após o surgimento da fotografia e do cinema, ela passa a ser criada para a exposição. Com a fotografia, o valor de exposição se sobressai em relação ao valor de culto; todavia, este resiste no rosto humano, isto explica o porquê de o retrato ser tema principal para os fotógrafos. Quando o rosto se ausenta da fotografia, o valor de exposição supera o valor de culto. Ao retirar o rosto humano da fotografia e ao inserir paisagens, a obra de arte ganha uma função que é a política, uma vez que se transforma em provas para a história, além de orientar a recepção por meio das legendas. $\mathrm{O}$ primeiro fotógrafo que deixou de registrar o rosto humano para registrar as paisagens foi Atget, em 1900. Sobre este fotógrafo, Benjamin (1994, p. 175) diz:

Com justiça, escreveu-se dele que fotografou as ruas como quem fotografa o local de um crime. Também esse local é deserto. É fotografado por causa dos indícios que ele contém. Com Atget, as fotos se transformam em autos no processo da história. Nisso está sua significação política latente. Essas fotos orientam a recepção num sentido predeterminado. A contemplação livre não the é adequada. Elas inquietam o observador, que pressente que deve seguir um caminho definido para se aproximar delas.

As legendas tornam-se mais precisas no cinema, uma vez que para compreender uma imagem é preciso entender as anteriores. O filme é uma obra de arte perfeita, uma vez que vários especialistas interferem nele durante seu processo de produção, buscando justamente sua perfeição; diante disso, o filme é produto de uma montagem, de uma junção de imagens fragmentadas colocadas em sequência. No entanto, para os gregos, que visavam à produção dos valores eternos, a escultura possuía o status da mais alta arte, feita a partir de um único bloco. A escultura entra em declínio a partir da criação da arte montável.

A fotografia e o cinema mudaram a natureza da arte. Um quadro é uma obra de arte, a foto desse quadro não é uma obra de arte. O estúdio em que a cena cinematográfica acontece não é obra de arte, sua reprodução também não o é. Mesmo assim, a arte surge na montagem. 
Para o autor, "A obra de arte surge através da montagem, na qual cada fragmento é a reprodução de um acontecimento que nem constitui em si uma obra de arte, nem engendra uma obra de arte ao ser filmado" (BENJAMIN, 1994, p. 178).

$\mathrm{O}$ ator de cinema não se apresenta para o público, mas para o aparelho e para os especialistas que interferem durante a encenação. O montador irá escolher a melhor cena para inseri-la no filme. $\mathrm{O}$ ator de cinema se apresenta diante do aparelho, ele não representa. $\mathrm{O}$ diretor controla o ator, que se sente alienado de si e do público. A estranheza que o ator de cinema sente é a mesma que o ser humano sente ao se olhar no espelho durante o período romântico. $\mathrm{O}$ ator se transformará em uma imagem que será apresentada para as massas por meio de uma tela de cinema ou televisão. O ator sabe disso desde o início. As massas controlam a ação do ator e a utilização política disso só acontecerá quando o cinema se libertar do capitalismo.

$\mathrm{O}$ ator de cinema não é um bom ator, já que ele se apresenta diante do aparelho, o que abre a possibilidade para que pessoas comuns possam fazer cinema - e este emprega mais pessoas do que o teatro. Assim como o ator de teatro, o político profissional também entra em crise na era da reprodutibilidade. O político se expressa também para o aparelho e não para o parlamento, que se atrofia. O parlamento não mais controla o político, quem o faz é o aparelho, disso emerge o ditador na política e o astro no cinema.

No cinema todos podem emitir julgamento como se fossem especialistas. O cinema movimenta as imagens sem esforço e as apresenta para um grande público, mas cada espectador contempla a imagem de modo individual. Não há ilusão no cinema quando participamos do seu processo de montagem, uma vez que é possível ver os aparelhos técnicos necessários para sua produção. No cinema, a ilusão surge como resultado da montagem.

Dessa forma, o filme não é a realidade, mas é o resultado de uma montagem. A imagem no cinema se move e o espectador não pode se distrair: se fizer isso, não entenderá o filme. Ao observar uma imagem, ela já se foi. Dessa forma, para entender um filme é necessário estar atento. As massas entendem as obras de arte enquanto distração ou diversão. Já o conhecedor busca nas obras o recolhimento, as obras são devoção para o conhecedor que mergulha na obra e se dissolve nela. As massas não fazem isso, elas não observam as obras por meio da atenção, mas por meio de distração e diversão.

A função da arte é criar um equilíbrio entre o ser humano e o aparelho. O homem se apresenta diante do aparelho, ao mesmo tempo em que representa o mundo por meio do aparelho. Antes do cinema, as imagens que a sociedade tinha eram aquelas do cotidiano, mas o cinema trouxe imagens além dele. A câmera apresenta um espaço diferente do apresentado pelo olho, ela apresenta um espaço no qual a ação humana é inconsciente.

Diante do que foi exposto, concluímos que a cultura é um tema fundamental para o estudo sobre a valorização subjetiva do espaço. Mas esse estudo não para por aí. O objetivo é a compreensão da valorização objetiva do espaço. A cultura é todo tipo de conhecimento, representações, práticas criadas pela sociedade ao longo do tempo e espaço. Com o surgimento da indústria cultural, por intermédio dos meios de comunicação, a cultura incide a ser produzida para o mercado, a fim de estimular o consumo e as necessidades, ou seja, a cultura se transforma em mercadoria e passa a estimular a produção de outras mercadorias. 
Essa cultura industrializada criada pela indústria cultural veicula concepções pejorativas sobre paisagens, lugares e povos não hegemônicos. A arte na Modernidade possui a possibilidade de ser reproduzida em série, isso abre para várias possibilidades, como apontou Benjamin (1994). De acordo com ele, é preciso libertar o cinema do capitalismo para que ele possa ser um instrumento de transformação social. Os autores da Teoria Crítica são fundamentais para o pensamento materialista histórico e dialético, eles escaparam de uma visão economicista do mundo, ou seja, um pensamento que coloca a cultura como resultado dos determinantes econômicos. O que há é uma intensa mediação entre a base material com as representações. No entanto, o próprio capitalismo transforma "tudo" em mercadoria. Defendemos a importância desses autores e dessa temática para o estudo da valorização objetiva do espaço, isto é, de uma Geografia Crítica dentro da proposta criada por Moraes (1988).

\section{REFERÊNCIAS}

ADORNO, Theodor; HORKHEIMER, Max. Dialética do esclarecimento: fragmentos filosóficos. Rio de Janeiro: Jorge Zahar Editor, 1985.

BENJAMIN, Walter. Magia e técnica, arte e política: ensaios sobre a literatura e história da cultura. São Paulo: Brasiliense, 1994.

COELHO, Teixeira. O que é indústria cultural. São Paulo: Brasiliense, 1986.

MCLUHAN, Marshall. Os meios de comunicação como extensões do homem. São Paulo: Cultrix, 1964.

MORAES, Antonio Carlos Robert de. Ideologias geográficas: espaço, cultura e política no Brasil. 2. ed. São Paulo: Hucitec, 1988.

MORAES, Antonio Carlos Robert de; COSTA, Wanderley Messias da. Geografia crítica: a valorização do espaço. São Paulo: Hucitec, 1984.

SAID, Edward W. Cultura e imperialismo. Tradução Denise Bottmann. São Paulo: Companhia da Letras, 2011.

\section{COMO CITAR ESTE TRABALHO}

SETIN, Monique Fernanda. Ideologias Geográficas e Indústria Cultural. Revista Tamoios, São Gonçalo, v. 17, n. 2, p. 47-58, 2021. Disponível em: https://doi.org/10.12957/tamoios.2021.60783. Acesso em: DD MM. AAAA. 